\title{
Appreciation of Artistic Genres in Children with Different Perceptual, Contextual and Analytic Intelligence
}

\author{
K. V. Lilly and Sudhakar Venukapalli
}

\section{ABSTRACT}

Children feel wonder and excitement while perceiving an artwork and their aesthetic responses are evident through their spontaneous expressions. During this process, children understand multiple interpretations of familiar themes. Children's descriptions of artworks are categorised into three levels of appreciation namely, perceptual level, contextual level and analytical level. The objective of the present study is to explore children's appreciation of art. The quantitative study investigates children's descriptions of artworks at various levels of art appreciation. The study employs sixty grade IX children from the state of Telangana. The sample selected include equal number of boys and girls from rural and urban areas and they are in the age group of 13-15 years. The stimuli used in the study are artworks depicting landscapes selected from three artistic genres of representational, semi-representational and abstract artworks. Images of artworks are presented randomly to children to elicit their responses. The results of the study showed that representational artworks are better appreciated by children than semirepresentational and abstract artworks. The analysis of children's expressions of artworks at various levels of appreciation reveals that for all three genres of artworks, children are at the perceptual level of appreciation. Statistical analysis of the results illustrates that there are statistically significant differences in appreciation at the perceptual, contextual, and analytical levels of appreciation of three genres of artworks. The findings of the study may be used by educators in providing art learning experiences to children.

Keywords: Art, art appreciation, beauty, culture.
Published Online: June 16, 2021

ISSN: $2736-4534$

DOI : $10.24018 /$ ejedu.2021.2.3.102

K. V. Lilly

Department of Education, The English and Foreign Languages University, Hyderabad, India.

(e-mail: lillychacko@gmail.com)

Sudhakar Venukapalli*

Department of Education, The English and Foreign Languages University, Hyderabad, India.

(e-mail:

sudhakarvenu.efluniversity@gmail.com)

*Corresponding Author

\section{INTRODUCTION}

Experience and appreciation of beauty in art works is a function of one's cognitive and non-cognitive resources and states. One's state of mind and body regulates how one perceives, experiences, and appreciates beauty and art. David Hume [1] argues that "Beauty is no quality in things themselves: it exists merely in the mind which contemplates them; and each mind perceives a different beauty." Alexander Baumgarten [2], who coined the term aesthetics in 1750 argued that certain physical properties of an object may evoke a sense of beauty, but aesthetic experience is solely a mindful event. Many theorists have claimed that the only purpose of art is to create objects that bring feelings of beauty, i.e., to instil aesthetic response. It is suggested that "aesthetic experiences in childhood have lasting mental and emotional effects even in adulthood and it foster development of artistic taste" [3].

In modern terms, the processing fluency theory provides the most powerful explanation of aesthetic appreciation [4]. The fluency theory suggests that the mechanism of mental ease explains how aesthetic pleasure is obtained from art [5]-[7]. Ramachandran \& Hirstein [8] suggested that "an object discovered after a struggle is more pleasing than one that is instantly obvious". It was also found that "experiencing art invokes a range of affective states like surprise, curiosity, insight, awe and even shocks" [9]-[11]. These features cannot be explained in terms of fluency theory [12], [13]. Leder et al. [14] argued that providing additional information to viewers which help them in understanding the paintings does not influence preference of paintings.

Over the years various psychologists and theorists have proposed a wide range of theories to explain art/aesthetic appreciation. Read [15] contends that "when we contemplate a work of art, we project ourselves into the form of the work of art and our feelings are determined by what we find there, by the dimensions we occupy". From twentieth century onwards, empirical psychologists have tried to study the claim that aesthetics could be investigated scientifically. Psychologists have looked for people's aesthetic responses to different kinds of stimuli. Many studies conducted later agreed with this view and concluded that "aesthetic preferences and beauty are, at least in part, universal and innate" [16]. 


\section{CHILDREN'S APPRECIATION OF ART}

Though children from different age groups respond in different ways, psychologists have contended that “children's familiarity with art and their individual experiences (including the use of artistic medium and awareness of art in cultural and historic context) influence their aesthetic development" [17]-[20]. Kerlavage [21] had proposed that there are three progressive and sequential stages for the development of young children's ideas about art - "their personal preferences of art, reasons for their preferences, concepts of artistic style and verbal responses. They are the sensorial, the concrete and the expressive stage" [22].

Most researchers agree that "art provides pleasing, hedonic experiences" [23], [24]. Art appreciation is often regarded as a subjective experience. Empirical research in art appreciation has led us into an understanding of the nature of art appreciation. Traditionally, art appreciation focused on the intrinsic values of art and centred on appreciation of artistic elements. It includes "composition, form, colour, light and space." Art appreciation includes varied activities including the ways of responding to an artwork, interpreting an artwork, and understanding the artwork that aims at its meaning. It is a mental process that encompasses identifying various forms of perception and presentation portrayed in the artwork. Moxey [25], [26] argued that "visual appreciation, how a work of art is presented, represented and perceived" should also be incorporated into art appreciation.

Children articulate their wonder and excitement while perceiving an artwork and their aesthetic responses are evident through their spontaneous expressions. During this process, children understand multiple interpretations of familiar themes. This implies that children who are exposed to quality art over a period of time exhibits higher levels of aesthetic appreciation [27]. This helps children to develop perceptual and aesthetic skills [28] and also to "develop the seamless synthesis of perceiving, feeling, and thinking, which is an important aim of education and art education in particular [29]. It is found that when children are exposed to visual arts at an early stage, it helps sensory and perceptual development which acts as a foundation for early learning [30], [31].

Children's descriptions of artworks are categorized into three levels of appreciation namely, perceptual level, contextual level and analytical level based on Machotka's [32] study. These levels presume the cognitive developmental stages described by Piaget. When children focus on what they perceive in the painting and describe it, it is named as Perceptual level. Children's appreciation at this level is mainly based on subject matter and colour. If children can look at the painting as a whole, combining various elements, it is the Contextual level. At this level, children look for realistic presentation and clarity of presentation. When children use abstract language to describe the painting, it is identified as Analytical level. They interpret the meaning of artworks, and their appreciation of artworks is based on style, composition, and affective tone. Generally, children lack experience with original artwork. To view art and comprehend it, children should develop the skill which requires time and effort.
Savva \& Trimis [33] argues that "visits to art museums and other places of cultural interest" may help children in acquiring this skill. Individual and school experiences of children also play a vital role in understanding art. Housen [34] argued that "a well-chosen work of art is a selfcontained world" and children will be benefited from the discussion of such artworks, and they do not require specific background knowledge.

Several studies conducted in the field of art-based interventions in shaping new pedagogies for teaching proved that it enhances learning process among students. Rieger \& Chernomas [35] argued that art-based pedagogy that integrates art with other subject matter improves the learning process. Further, art-based learning was found to be effective in enhancing students' "observational skills, empathy, non-verbal communication and interpersonal skills" [36]. Art appreciation helps students to engage in expressing their own feelings and ideas and appreciate their own artistic creations [37], [38]. Art appreciation as part of art education can "widen the vision of students" [26]. It also helps children develop communication skills [39] and generate self-confidence [40].

Studies on art viewing specifically focuses on the value of "looking at art and talking about artworks" [41], [42]. Herbert Read argues that the basic error of all educational systems and their methods is in their focus on rational thinking. Read finds that harmony and balance in the child's personal integrity can be maintained through aesthetic culture and training him to live in a creative and natural manner can be achieved only through arts education [43]. Education in general and art education in particular is a way for one to grow and become sensitive to the beauty in nature, of social values and the aesthetic aspects of life as whole [44].

Viewing and experiencing art may help children become self-directed learners to enrich the creative and innovative thinking processes that are valued as $21^{\text {st }}$ century skills [45]. Gardner [46] argues that art draws from multiple intelligences to conceptualize, associate, and synthesize prior experience in creating new knowledge. Experiencing art is considered as an epistemology for finding meaning in life since viewing and discussing art stimulates imagination and foster envisioning what a better world would look like. It may promote positive social change by providing insight and hep in developing meaning in art and in life. If transference occurs, children may begin to analyze art with more insight, analyze the world with more curiosity, empathy thus creating an inclusive world.

Research suggested that "when viewing abstract artworks, young children responded intuitively and positively" [33], [42]. This is also in conformity with the view that "children apply their imagination in finding new meaning in artworks" [33], [47]. Ramsey [48] argued that most of elementary school children's preference was for realistic artworks rather than abstract ones. Research also identified that content engages children's attention as: "people, objects, actions, interactions, settings, gestures, emotions, and expressions" [27], [49], [50].

A study performed by Lye, Garces-Bascal \& Wright [22] found that children in the age group of 5-6 years named, described, expanded, and elaborated on their observations. 
They provided comments about artworks that featured "content, formal art elements, personal connections, creativity and imagination, affect and vocalisms, with personal connections." Eisen et al. [51] in their study found that children from 5 to 17 years preferred representational art. Therefore, the study of how children view and appreciate artworks is of importance for teachers and teacher educators.

\section{THE OBJECTIVES OF THE STUDY}

The objective of the present study is to explore children's appreciation of art. The quantitative study investigates children's descriptions of artworks at various levels of art appreciation. The study employs sixty grade IX children from the state of Telangana. The children selected are equal number of boys and girls from rural and urban areas and they are in the age group of 13-15 years.

The mean age for rural children is 14.7 years with a standard deviation of 0.58 whereas the mean age of urban children is 13.6 years with a corresponding standard deviation of 0.56 . On the other hand, the mean age for girls and boys are 14 years and 14.3 years respectively with a corresponding standard deviation of 0.91 and 0.81 . Overall, the mean age of the sample is 14.2 years with a standard deviation of 0.81 . The age range for all children are 13-15 years.

The sample consists of art naïve participants without any prior systematic art education. This helps to remove any mediated effect of art related knowledge [14]. The children are initially informed about art appreciation, paintings by various artists, paintings belonging to different artistic genres and the procedures involved in the study.

\section{STIMUli USEd IN THE STUdy}

To measure children's levels of art appreciation, children are shown nine images of landscapes. Landscapes depict a scenic view which includes hills, mountains, river, forests etc. These landscapes belong to the artistic genres of representational, semi-representational and abstract artworks. The representational artworks present the landscape in a realistic way. In a semi-representational artwork, the landscape appears realistic from far but when comes close, the brushstrokes seem to be slightly distorted. In abstract artworks, colour, line, and form are distorted and there is no similarity to an actual landscape. The artworks include western, middle eastern and oriental paintings. The artworks are selected based on relevant books on art history and with an intersubjective agreement of art experts. The artworks characterize specific artistic periods: Renaissance/Baroque, Impressionism and Abstraction. One of the important variables that affect art appreciation was identified as 'the level of abstractedness', from purely abstract to representative artworks [52]. This rationalizes the use of images of different types of paintings from varied artistic genres.

\section{Methodology}

The nine images of paintings are randomly shown to children using a projector. Images of artworks are presented in uncompressed jpg file colour format and all images are reduced in size to 1024 pixels. Few sample images of paintings are presented to children before the actual study to familiarize them with the procedure. These sample images are not included in the actual study. The images of artworks are shown for five to ten minutes to children to elicit their responses. The children are prompted to describe the paintings ranging from concrete descriptions of what they see to more abstract emotional reactions. Children's appreciation of artworks is obtained from their descriptions of artworks.

To ensure reliability of the study, all test procedures are conducted in a similar pattern for all participants. This might result in producing precise and stable results. The conditions of the tests are standardized, and external factors are minimized by providing consistent circumstances. Sample are selected from the same grade, age group and geographic location to produce valid results of the study.

Children's expressions of artworks are coded on a continuous scale of 1-10 for obtaining the level of appreciation. Their descriptions are categorized into three levels of appreciation [32]: Perceptual level, Contextual level, and Analytical level. When children focus on what they perceive in the painting and describe it, it is coded as Perceptual level. If children view the painting as a whole, combining various elements, it is coded as Contextual level. When children use abstract language to describe the painting, it is coded as Analytical level.

Children's descriptions of artworks are scored on a continuous scale of 1 to 10 for all three genres of artwork. For each genre of artwork and type of painting, children's descriptions are also coded for three levels of appreciation namely perceptual level, contextual level, and analytical level. Scores are given on a continuous scale of 1 to 10 for each level of appreciation.

The data obtained is tested for normality using ShapiroWilk test. From the $\mathrm{p}$ value, it is assumed that the data is non-normal. Therefore, non-parametric statistical tests are conducted for data analysis. Friedman test is conducted to compare the differences between perceptual, contextual, and analytical levels of appreciation for three genres of artworks. Post-Hoc test using Wilcoxon signed ranks test by applying Bonferroni adjustment is also conducted between different combinations of levels of appreciation to examine where the differences occur.

\section{RESUlts OF THE STUdY}

\section{A. Children's Appreciation of Artworks by Genre}

At the first level, the overall descriptions of artworks on a continuous scale of 1 to10 are tabulated for representational, semi-representational and abstract artworks. This figure will give us an insight into the overall art appreciation pattern of children. The total scores of children for representational, semi-representational and abstract artworks are given below: 


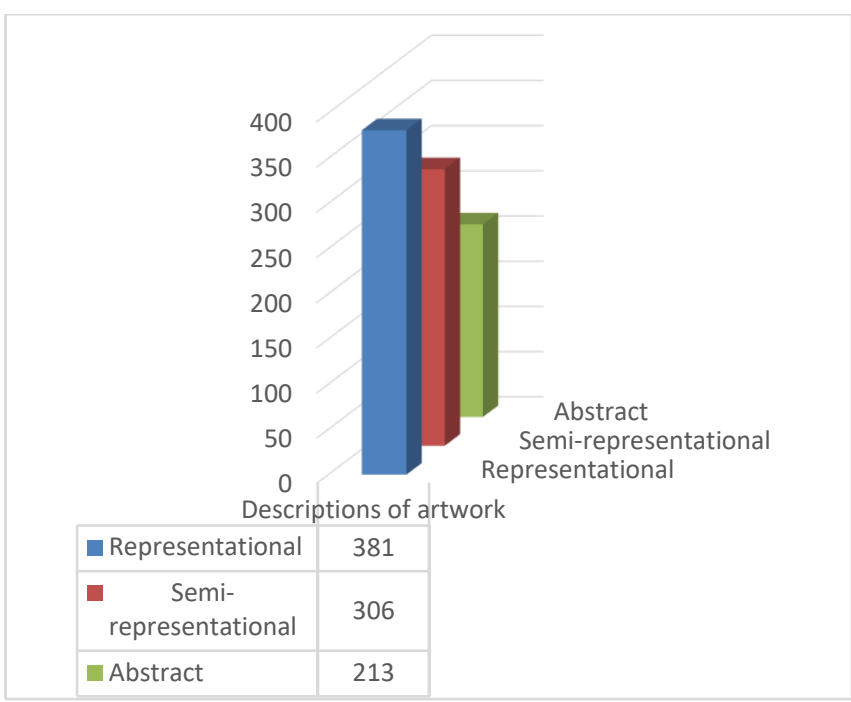

Fig. 1. Overall appreciation of artworks by genre.

The analysis of the overall appreciation of three genres of artworks shows that the total scores for appreciation of representational, semi-representational and abstract artworks are 381,306 and 213, respectively. It is evident from the results that the scores of appreciations of representational artworks are higher than the other two genres of artworks.

For each genre of artwork, children's descriptions are also coded for three levels of appreciation namely perceptual level, contextual level, and analytical level. Scores are given on a continuous scale of 1-10 for each level of appreciation. Results of the analysis of overall appreciation of artworks with respect to the three levels are given below.

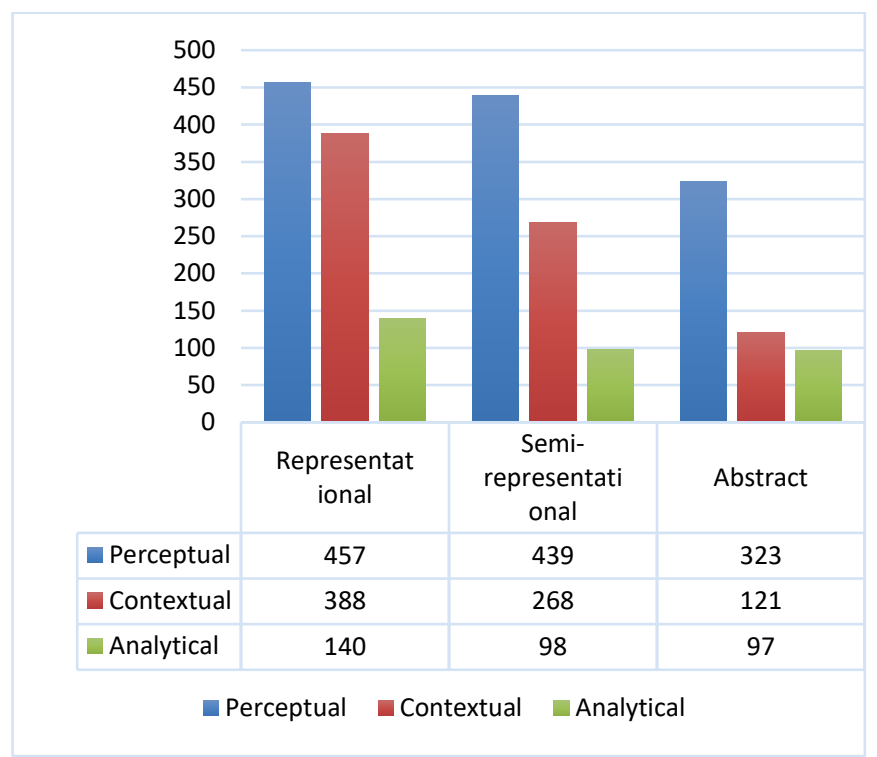

Fig. 2. Level of appreciation by genre of artworks.

The analysis of children's appreciation of representational artworks with respect to level of appreciation shows that the total scores for perceptual, contextual, and analytical level of appreciation are 457, 388 and 140, respectively. Children's scores for semi-representational artworks at perceptual, contextual, and analytical levels of appreciation are 439, 268 and 98, respectively. Children's scores for abstract artworks at perceptual, contextual, and analytical levels of appreciation are 323, 121 and 97, respectively.

The above results show differences in children's level of appreciation with respect to representational, semirepresentational and abstract artworks.

\section{B. Level of Appreciation by Genre - representational Artworks}

The analysis of children's appreciation of representational art works shows that there is a difference in the perceptual, contextual, and analytical level of appreciation. It is therefore necessary to assess if the differences in the level of appreciation is statistically significant or not. Hence, the following hypothesis is formulated:

$\mathrm{H}_{1}$ : There is a significant difference in children's appreciation at perceptual, contextual, and analytical level of appreciation of representational artworks.

To test this hypothesis, the above hypothesis is translated into null form.

$\mathrm{H}_{0}$ : There is no significant difference in children's appreciation at perceptual, contextual, and analytical level of appreciation of representational artworks.

Friedman test is employed to test the null hypothesis and the results are presented below:

TABLE I: FRIEDMAN TEST RESULTS - LEVEL OF APPRECIATION BY GENREREPRESENTATIONAL ARTWORKS

\begin{tabular}{ccccc}
\hline \multicolumn{5}{c}{ REPRESENTATIONAL ARTWORKS } \\
\hline $\begin{array}{c}\text { Representational } \\
\text { artworks }\end{array}$ & $\mathrm{N}$ & 25th & $\begin{array}{c}\text { Percentiles } \\
\text { 50th (Median) }\end{array}$ & 75th \\
\hline Perceptual & 60 & 7.0000 & 8.0000 & 8.0000 \\
Contextual & 60 & 6.0000 & 7.0000 & 8.0000 \\
Analytical & 60 & 1.0000 & 1.0000 & 3.7500 \\
\hline
\end{tabular}

\begin{tabular}{cc} 
TABLE II: TEST STATISTICS & FRIEDMAN TEST \\
\hline $\mathrm{N}$ & 60 \\
Chi-Square & 97.638 \\
$\mathrm{df}$ & 2 \\
Asymp. Sig. & .000 \\
\hline
\end{tabular}

The above table shows that $\chi^{2}$ value at 2 degrees of freedom is 97.638 and the significance level is 0.000 . Since $\mathrm{p}$ value is 0.000 , the null hypothesis stands rejected. Therefore, it is inferred that there is a statistically significant difference in the level of appreciation of representational artworks, $\chi^{2}(2)=97.638, p=0.000$.

To examine where the differences occur, a separate Wilcoxon signed ranks test is conducted on different combinations of the level of appreciation.

\begin{tabular}{|c|c|c|c|}
\hline $\begin{array}{c}\text { Representational } \\
\text { artworks }\end{array}$ & $\begin{array}{c}\text { Perceptual - } \\
\text { Contextual }\end{array}$ & $\begin{array}{c}\text { Perceptual- } \\
\text { Analytical }\end{array}$ & $\begin{array}{c}\text { Analytical - } \\
\text { Contextual }\end{array}$ \\
\hline $\mathrm{Z}$ & $-3.929^{b}$ & $-6.658^{b}$ & $-6.588^{b}$ \\
\hline $\begin{array}{l}\text { Asymp. Sig. (2- } \\
\text { tailed) }\end{array}$ & .000 & .000 & .000 \\
\hline
\end{tabular}

The above table provides the results of post-hoc analysis using Wilcoxon signed ranks test (with a Bonferroni correction applied, significance level is set at $p<0.017$ ) on each of the combinations. Median (Inter Quartile Range) descriptions of representational artworks at perceptual, contextual, and analytical level of appreciation are 8.0 (7 to 8), 7.0 (6 to 8 ) and 1.0 (1 to 3.75) respectively. The results show that there are statistically significant differences between children's appreciations at the perceptual and contextual level $(\mathrm{Z}=-3.929, \mathrm{p}=0.000)$, perceptual and analytical level $(\mathrm{Z}=-6.658, \mathrm{p}=0.000)$ and analytical and 
contextual level $(\mathrm{Z}=-6.588, \mathrm{p}=0.000)$.

\section{Level of Appreciation by Genre - semi- Representational Artworks}

The analysis of children's appreciation of semirepresentational art works (Fig. 2) shows that there are differences at the perceptual, contextual, and analytical level of appreciation. It is therefore required to assess if the differences in the level of appreciation is statistically significant or not. Hence, the following hypothesis is formulated:

$\mathrm{H}_{1}$ : There is a significant difference between children's appreciation at the perceptual, contextual, and analytical level of appreciation of semi-representational artworks.

To test this hypothesis, the above hypothesis is translated into null form.

$\mathrm{H}_{0}$ : There is no significant difference between children's appreciation at the perceptual, contextual, and analytical level of appreciation of semi-representational artworks.

Friedman test is used to test the null hypothesis and the results are presented below:

TABLE IV: FRIEDMAN TEST RESULTS - LEVEL OF APPRECIATION BY

\begin{tabular}{ccccc}
\multicolumn{2}{c}{ GENRE- SEMI-REPRESENTATIONAL ARTWORKS } \\
\hline $\begin{array}{c}\text { Semi- } \\
\text { representational } \\
\text { artworks }\end{array}$ & $\mathrm{N}$ & 25 th & 50th (Median) & 75 th \\
\hline Perceptual & 60 & 7.0000 & 7.0000 & 8.0000 \\
Contextual & 60 & 3.0000 & 5.0000 & 6.0000 \\
Analytical & 60 & 1.0000 & 1.0000 & 2.7500 \\
\hline
\end{tabular}

\begin{tabular}{cc} 
TABLE V: TEST STATISTICS - FRIEDMAN TEST \\
\hline $\mathrm{N}$ & 60 \\
Chi-Square & 109.542 \\
df & 2 \\
Asymp. Sig. & .000 \\
\hline
\end{tabular}

From the above table, it is observed that $\chi^{2}$ value at 2 degrees of freedom is 109.542 and the significance level is 0.000 . Since $\mathrm{p}$ value is 0.000 , the null hypothesis stands rejected. Therefore, it is inferred that there is a statistically significant difference in children's appreciation at the perceptual, contextual, and analytical level of appreciation of semi-representational artworks, $\chi^{2}(2)=109.542, \mathrm{p}=$ 0.000 .

To examine where the differences occur, a separate Wilcoxon signed ranks test is performed on different combinations of the level of appreciation.

\begin{tabular}{lccc}
\multicolumn{4}{c}{ TABLE VI: TEST STATISTICS - WILCOXON SIGNED RANKS TEST } \\
\hline $\begin{array}{c}\text { Semi- } \\
\text { representational } \\
\text { artworks }\end{array}$ & $\begin{array}{c}\text { Perceptual - } \\
\text { Contextual }\end{array}$ & $\begin{array}{c}\text { Perceptual- } \\
\text { Analytical }\end{array}$ & $\begin{array}{c}\text { Analytical - } \\
\text { Contextual }\end{array}$ \\
\hline $\begin{array}{c}\text { Z } \\
\text { Asymp. Sig. }(2- \\
\text { tailed) }\end{array}$ & $-6.414^{\mathrm{b}}$ & $-6.825^{\mathrm{b}}$ & $-6.251^{\mathrm{b}}$ \\
$\mathrm{c}$ & .000 & .000 & .000 \\
\hline Based on positive ranks. & &
\end{tabular}

b. Based on positive ranks.

The above table provides the results of post-hoc analysis using Wilcoxon signed ranks test (with a Bonferroni correction applied, significance level is set at $p<0.017$ ) on each of the combinations. Median (Inter Quartile Range) descriptions of semi-representational artworks at perceptual, contextual, and analytical level of appreciation are 7.0 (7 to 8), 5.0 (3 to 6) and 1.0 (1 to 2.75 ) respectively. The results show that there are statistically significant differences between children's appreciation at the perceptual and contextual level $(\mathrm{Z}=-6.414, \mathrm{p}=0.000)$, perceptual and analytical level $(Z=-6.825, p=0.000)$ and analytical and contextual level $(\mathrm{Z}=-6.251, \mathrm{p}=0.000)$ of appreciation of semi-representational artworks.

\section{Level of Appreciation by Genre - abstract Artworks}

The analysis of the appreciation of abstract art works (Fig. 2) shows that there are differences in children's appreciation at the perceptual, contextual, and analytical level of appreciation. It is therefore required to assess if the differences in the level of appreciation is statistically significant or not. Hence, the following hypothesis is formulated:

$\mathrm{H}_{1}$ : There is a significant difference between children's appreciation at the perceptual, contextual, and analytical level of appreciation of abstract artworks.

To test this hypothesis, the above hypothesis is translated into null form.

$\mathrm{H}_{0}$ : There is no significant difference between children's appreciation at the perceptual, contextual, and analytical level of appreciation of abstract artworks.

Friedman test is employed to test the null hypothesis and the results are shown below:

TABLE VII: FRIEDMAN TEST RESULTS - LEVEL OF APPRECIATION BY GENRE-ABSTRACT ARTWORKS

\begin{tabular}{ccccc}
\hline \multirow{2}{*}{ Abstract artworks } & \multirow{2}{*}{$\mathrm{N}$} & \multicolumn{3}{c}{ Percentiles } \\
\cline { 3 - 5 } & & 25th & 50th (Median) & 75th \\
\hline Perceptual & 60 & 5.0000 & 6.0000 & 6.0000 \\
Contextual & 60 & 1.0000 & 1.0000 & 3.0000 \\
Analytical & 60 & 1.0000 & 1.0000 & 2.0000 \\
\hline
\end{tabular}

\begin{tabular}{cc} 
TABLE VIII: TEST STATISTICS & FRIEDMAN TEST \\
\hline $\mathrm{N}$ & 60 \\
Chi-Square & 102.422 \\
$\mathrm{df}$ & 2 \\
Asymp. Sig. & .000 \\
\hline
\end{tabular}

The results in the above table show that $\chi^{2}$ value at 2 degrees of freedom is 102.422 and the significance level is 0.000 . Since $\mathrm{p}$ value is 0.000 , the null hypothesis stands rejected. Therefore, it is inferred that there is a statistically significant difference in children's appreciation at perceptual, contextual, and analytical level of appreciation of abstract artworks, $\chi^{2}(2)=102.422, p=0.000$.

To examine where the differences occur, a separate Wilcoxon signed ranks test was conducted on different combinations of the level of appreciation.

\begin{tabular}{cccc}
\multicolumn{4}{c}{ TABLE IX: TEST STATISTICS - WILCOXON SIGNED RANKS TEST } \\
\hline Abstract artworks & $\begin{array}{c}\text { Perceptual - } \\
\text { Contextual }\end{array}$ & $\begin{array}{c}\text { Perceptual- } \\
\text { Analytical }\end{array}$ & $\begin{array}{c}\text { Analytical - } \\
\text { Contextual }\end{array}$ \\
\hline $\begin{array}{c}\text { Z } \\
\text { Asymp. Sig. (2- } \\
\text { tailed) }\end{array}$ & $-6.606^{\mathrm{b}}$ & $-6.709^{\mathrm{b}}$ & $-2.765^{\mathrm{b}}$ \\
\hline
\end{tabular}

b. Based on positive ranks.

The above table provides the results of post-hoc analysis using Wilcoxon signed ranks test (with a Bonferroni correction applied, significance level is set at $p<0.017$ ) on each of the combinations. Median (Inter Quartile Range) descriptions of abstract artworks at perceptual, contextual, and analytical level are 6.0 (5 to 6$), 1.0$ (1 to 3 ) and 1.0 (1 to 
2) respectively. The results show that there are statistically significant differences between children's appreciation at the perceptual and contextual level $(Z=-6.606, p=0.000)$, perceptual and analytical level $(Z=-6.709, p=0.000)$ and analytical and contextual level $(\mathrm{Z}=-2.765, \mathrm{p}=0.006)$ of appreciation of abstract artworks.

\section{FINDINGS AND DISCUSSION}

The scores obtained by children for the appreciation of representational artworks are a clear indication that children highly appreciated representational artworks compared to the other two genres of artworks. This is corroborated with the finding that classical art has clear content, and it is better understood by viewers [52]. The analysis of children's expressions of artworks reveals that for all three genres of artworks, children's scores of appreciations is higher for perceptual level of appreciation. Children's expressions at the contextual level are notably present for representational and semi-representational artworks though lower than perceptual level and children scored extremely low at the analytical level of appreciation. Statistical analysis of the results illustrates that there are statistically significant differences in the perceptual, contextual, and analytical levels of appreciation of three genres of artworks.

The results of the study agree with previous studies which suggests that children's descriptions of representational artworks are more than that of semi-representational and abstract artworks. The results also support the past findings that children's appreciation of artworks varies depending on the genre of painting. The more realistic the painting, the more children focus on what they see in the artwork and comprehend the artwork. Children find difficulty in understanding and describing abstract artworks. This corroborates the findings by Leder \& Nadal [53] that aesthetic appreciation of artworks depends strongly on aspects of cognitive mastering. This results also agrees with Leder et. al.'s [54] hypothesis that comprehension of an artwork depends on content representation in the artwork and representative classical artworks were comprehended better by viewers [52].

The results presented above reveal that children express what they see in the painting and are mostly at the perceptual level of appreciation. They describe what makes them feel good and happy. They relate artworks to their personal feelings, culture, and environment. This corroborates the view that when viewing artworks, lay people are interested in what make them feel good and what elicits emotions [55]. In the case of abstract artworks where there is no clear subject matter or content, children tried to find meaning and interpretation in their own ways. This confirms the finding that children make meaning from what they see, and children can articulate their thoughts and ideas [22].

But the results of the present study are not in conformity with the results of Machotka's [32] art appreciation progression. Machotka argued that children above 12 years of age who are in the formal operational stage as per Piaget's cognitive development model appreciates artworks based on interest in style, composition, affective tone and luminosity and they are expected to be at the Analytical level. But our results show that children try to look at the artwork as a whole and looks for realistic presentation of the artwork. Most of the children focus more on what they see in the artwork while appreciating the artwork. Very few children appreciate the artworks based on style and composition. This may be explained on the basis of their experiences in art. None of the children are exposed to art theory and they have no prior expertise in art making. Few children have visited an art gallery or museum. It is evident from the art expertise questionnaire that they are art naïve. This confirms Parsons' [56] proposition that "the individual's development in art is influenced by cultural, educational and social aspects of experience." Though Parsons proposes a universal aesthetic development theory, he agrees with "the possibility of cultural differences in art appreciation". On the contrary, the results corroborate the findings of Wang \& Ishizaki [57] that the descriptions of artworks by high school students in US were dominated by subject matter and they described what they saw in the painting.

\section{CONCLUSION}

The present study reveals that children can meaningfully engage with artworks from different artistic genres. Children described artworks and presented their observations in detail. We need artworks that reflect beauty and portray human experiences in order for humankind to evolve. Artworks challenges mind and inspires our understanding. A world without art would hinder growth and development in children. Children's engagement with works of art and experiencing artworks amounts to active learning. Providing opportunities for children to experiencing artworks may help children develop meaning in life and facilitates positive social change. Educational institutions should find novel ways of providing the benefits of art to children. Engaging children with artworks would benefit children while in school and for the rest of their life.

The research findings are a clear indication that teachers should encourage children to engage with, reflect upon and value their experiences with artworks and its beauty. Teachers should provide opportunities for children to find beauty in artworks as well as in nature. Children should have opportunities to articulate their experiences of beauty and their reflections on artworks. Their aesthetic experiences should be broadened through different contexts provided in their curricular subjects including languages, mathematics, science, history, and the like.

\section{APPENDIX}

List of paintings:

1. Pastoral Landscape, Asher Brown Durand,1861, Hudson River School.

2. Water lilies, Claude Monet, 1917, Impressionism.

3. Landscapes with Red spots no. 2, Wassily Kandinsky, 1913, Abstraction.

4. An Arab encampment at Sunset, Herman David Salomon Corrodi.

5. Middle eastern city, unknown, Early $20^{\text {th }}$ century.

6. Abstract landscape, Shafic Abboud, 1959. 
7. The Watercolour Log, Milind Mulick, contemporary.

8. Dancing and Singing (Peasants Returning from Work), Ma Yuan, $13^{\text {th }}$ century.

9. The First Light, Chu Teh Chun, 1987.

\section{REFERENCES}

[1] Hume, D. (1898/1757). Of the standard of taste. In T. H. Green \& T. H. Grose (Eds.), Essays moral, political and literary. In Shimamura, A. P. (2012). Toward a science of aesthetics. In Shimamura, A.P. and Palmer, S.E. (Eds.), Aesthetic Science (pp 3-28). Oxford: Oxford University Press.

[2] Hugh, C. (Ed.).1911). "Baumgarten, Alexander Gottlieb". Encyclopcedia Britannica $\left(11^{\text {th }}\right.$ ed.). Cambridge University Press.

[3] Parc, J. \& Moon, H.C. (2019). Accumulated and Accumulable Cultures: A Case of Public and Private Initiatives Toward K-Pop. Kritika Kultura 32: 429-52. doi: 10.13185/2992.

[4] Palmer, S. E., Schloss, K. B., \& Sammartino, J. (2013). Visual aesthetics and human preference. Annual Review of Psychology, 64, 77-107. doi: 10.1146/annurevpsych-120710-100504.

[5] Reber, R., Schwarz, N., \& Winkielman, P. (2004). Processing fluency and aesthetic pleasure: Is beauty in the perceiver's processing experience? Personality and Social Psychology Review, 8(4):364-82 doi:10.1207/s15327957pspr0804_3.

[6] Reber, R., Winkielman, P., \& Schwarz, N. (1998). Effects of perceptual fluency on affective judgments. Psychological Science, 9 , 45-48. doi: 10.1111/1467-9280. 00008.

[7] Winkielman, P., Halberstadt, J., Fazendeiro, T., \& Catty, S. (2006). Prototypes are attractive because they are easy on the mind. Psychological Science, 17(9):799-806. doi:10.1111/j.14679280.2006. 01785.x.

[8] Ramachandran, V. S. \& Hirstein, W. (1999). The science of art: A neurological theory of aesthetic experience. Journal of Consciousness Studies, 6-7, 15-51. Retrieved from https://doi.org/10.1179/ 174327908 X392906.

[9] Kuspit, D. (2006). The Emotional Gains of Aesthetic Shock. Psychoanalytic Inquiry, 26(3): 344-361. doi: 10.2513/s07251690pi2603_5.

[10] Muth, C. \& Carbon, C. C. (2013). The aesthetic aha: on the pleasure of having insights into gestalt. Acta Psychologica, 144,25-30. doi: 10.1016/j.actpsy.2013.05.001.

[11] Silvia, P. J. (2009). Looking Past Pleasure: Anger, Confusion, Disgust, Pride, Surprise, and Other Unusual Aesthetic Emotions. Psychology of Aesthetics, Creativity, and the Arts, 3(1):48-51. doi:10.1037/A0014632.

[12] Armstrong, T., \& Detweiler-Bedell, B. (2008). Beauty as an emotion: the exhilarating prospect of mastering a challenging world. Review of General Psychology, 12, 305-329. doi:10.1037/a0012558.

[13] Frijda, N. H. (1989). Aesthetic Emotions and Reality. American Psychologist, $\quad 44,1546-1547 . h t t p: / / d x . d o i . o r g / 10.1037 / 0003-$ 066X.44.12.1546.

[14] Leder, H., Carbon, C. C., \& Ripsas, A. L. (2006). Entitling art: influence of title information on understanding and appreciation of paintings. Acta Psychologica, 121, 176-198. doi: 10.1016/j.actpsy.2005.08.005.

[15] Read, H. (1968). The Meaning of Art. Faber \& Faber. London.

[16] Renoult, J.P. (2016). The Evolution of Aesthetics: A Review of Models. In Kapoula Z., Vernet M. (Eds.), Aesthetics and Neuroscience. Springer, Cham. doi: https://doi.org/10.1007/978-3319-46233-2_17.

[17] Gardner, H., Winner, E., \& Kirchner, M. (1975). Children's conceptions of the Arts. Journal of Aesthetic Education, 9 (3), 60-77. Retrieved http://links.jstor.org/sici?sici=00218510\%28197507\%299\%3A3\%3C 60\%3ACCOTA\%3E2.0.CO\%3B2-F.

[18] Housen, A. (1987). Three methods for understanding museum audiences. Museum Studies Journal, 2(4), 41-50. Retrieved from https://vtshome.org/wp-content/uploads/2016/08/6-

3MethodsforMuseumAudiences.pdf.

[19] Lin, S.F. \& Thomas, G.V. (2002). Development of understanding of popular graphic art: A study of everyday aesthetics in children, adolescents and young adults. International Journal of Behavioural Development, 26(3): 278-287. doi: 10.1080/01650250143000157a.

[20] Taunton, M. (1982). Aesthetic responses of young children to the visual arts: A review of the literature. Journal of Aesthetic Education, 16(3):93-109. Retrieved from https://doi.org/10.2307/3332196.

[21] Kerlavage, M.S. (1995). A bunch of naked ladies and a tiger: Children's responses to adult works of art. In C. M. Thompson (Ed.),
The visual arts and early childhood. In Lye, J. W. Y., Garces-Bacsal, R. M., \& Wright, S. K. (2017). Young children's responses to artworks: The eye, the mind, and the body. International Journal of Education \& the Arts, 18(30). Retrieved from http://www.ijea.org/v18n30/.

[22] Lye, J. W. Y., Garces-Bacsal, R. M., \& Wright, S. K. (2017). Young children's responses to artworks: The eye, the mind, and the body. International Journal of Education \& the Arts, 18(30). Retrieved from http://www.ijea.org/v18n30/.

[23] Berlyne, D. E. (Ed.). (1974). Studies in the new experimental aesthetics: Steps toward an objective psychology of aesthetic appreciation. Washington, D.C.: Hemisphere Publishing Corporation. doi: https://doi.org/10.2307/3394907.

[24] Dissanayake, E. (2007). What art is and what art does: An overview of contemporary evolutionary hypotheses. In C. Martindale, P. Locher \& V. Petrov (Eds.), Evolutionary and neurocognitive approaches to aesthetics, creativity, and the arts (p. 1-14). Baywood Publishing Co.

[25] Moxey, K. (1996). Animating aesthetics: response to the visual culture questionnaire. In Law, S. S. M. (2010). An Interdisciplinary Approach to Art Appreciation. New Horizons in Education, 58(2). Retrieved from https://files.eric.ed.gov/fulltext/EJ966652.pdf.

[26] Law, S. S. M. (2010). An Interdisciplinary Approach to Art Appreciation. New Horizons in Education, 58(2). Retrieved from https://files.eric.ed.gov/fulltext/EJ966652.pdf.

[27] Housen, A. (2002). Aesthetic thought, critical thinking and transfer. Art and Learning Research Journal, 18, 99-132. Retrieved from https://pdfs.semanticscholar.org/f92a/f0a61718efaca853d456c1edec6 817dfee31.pdf?_ga=2.174320491.838978140.1577727629127502483.1577727629 .

[28] Zakaras, L. \& Lowell, J.F. (2008). Cultivating demand for the arts: Arts learning, arts engagement, and state arts policy. Rand Corporation. Retrieved from https://www.rand.org/content/dam/rand/pubs/monographs/2008/RAN D_MG640.pdf.

[29] Wright, S. (2003). The arts, young children, and learning. Boston: Allyn and Bacon. Retrieved from https://books.google.co.in/books/about/The_Arts_Young_Children_a nd_Learning.html?id=o0ydAAAAMAAJ\&redir_esc $=$ y.

[30] Dunn, J. \& Wright, S. (2014). Signs, meaning, and embodiment: Learning and pedagogy. In M. Fleming, L. Bresler, \& J. O-Toole (Eds.), International handbook of arts and education, International handbook of arts and education. Routledge, NY.

[31] Rudolf, S. \& Wright, S. (2015). Drawing out the value of the visual: children and young people theorizing time through art and narrative. Journal of Curriculum Studies, 47(4), 486-507. Retrieved from https://doi.org/10.1080/00220272.2015.1006685.

[32] Machotka, P. (1966). Aesthetic Criteria in Childhood: justifications of preference. Child Development, 37(4): 877-885. Retrieved from https://doi.org/10.2307/1126610.

[33] Savva, A. \& Trimis, E. (2005). Responses of young children to contemporary art exhibits: The role of artistic experiences. International Journal of Education and the Arts, 6(13). Retrieved from http://ijea.asu.edu/v6n13/.

[34] Housen, A. (2001). The eye of the beholder: Research, theory and practice. Paper presented at the conference of aesthetic and art education: A transdisciplinary approach, Lisbon, Portugal. Retrieved from http://www.vtshome.org/pages/vts-downloads.

[35] Rieger, K. L. \& Chernomas, W. M. (2013). Arts-based learning: analysis of the concept for nursing education. International Journal of Nursing Education Scholarship, 10, 53-62. doi: 10.1515/ijnes-20120034.

[36] Wikström, B.-M. (2011). Works of art as a pedagogical tool: an alternative approach to education. Creative Nursing, 17, 187-194. doi: 10.1891/1078-4535.17.4.187.

[37] Subramaniam, M. (2017). The development of a tertiary level visual communication module incorporating an art appreciation approach. In Ping, C. T. S. \& Ladin, C. A. (2019). Applications of Art Appreciation in Teaching and Learning in Primary School. International Journal of Academic Research in Progressive Education and Development, 8(4), 130-140. doi: 10.6007/IJARPED/v8-i4/6441.

[38] Madrid, D., Ahmed, U., \& Kumar, R. (2019). Examining the Impact of Classroom Environment on Entrepreneurship Education: Case of a Private University in Bahrain. In Ping, C. T. S. \& Ladin, C. A. (2019). Applications of Art Appreciation in Teaching and Learning in Primary School. International Journal of Academic Research in Progressive Education and Development, 8(4): 130-140. doi 10.6007/IJARPED/v8-i4/6441. 
[39] Novaković, S. (2015). Preschool teacher's role in the art activities of early and preschool age children. Croatian Journal of Education, 17(0). doi:10.15516/cje. v17i0.1497.

[40] Ariffin, M. S. N. (2010). Sejauhmana keberkesanan perlaksanaan sesi apresiasi seni di sekolah menengah dalam pendidikan seni. In Ping, C. T. S., \& Ladin, C. A. (2019). Applications of Art Appreciation in Teaching and Learning in Primary School. International Journal of Academic Research in Progressive Education and Development, 8(4): 130-140. doi: 10.6007/IJARPED/v8-i4/6441.

[41] Epstein, A. S. \& Trimis, E. (2002). Supporting young artists: The development of visual arts in young children. In Lye, J. W. Y., Garces-Bacsal, R. M., \& Wright, S. K. (2017). Young children's responses to artworks: The eye, the mind, and the body. International Journal of Education \& the Arts, 18(30). Retrieved from http://www.ijea.org/v18n30/.

[42] Savva, A. (2003). Young Pupil's Responses to Adult Works of Art. Contemporary Issues in Early Childhood, 4(3). doi: 10.2304/ciec.2003.4.3.6.

[43] Gilbert, K.E. \& Kuhn, H. (1967). History of aesthetics. In Denac, O. (2014). The significance and role of aesthetic education in schooling. Creative Education, 5(19). doi: 10.4236/ce.2014.519190.

[44] NCERT Country report 2010 Art Education in India. Retrieved from https://ncert.nic.in/deaa/pdf/1.pdf.

[45] Bellanca, J. A., \& Brandt, R.S. (2010). $21^{\text {st }}$ Century skills: Rethinking how students learn. Solution Tree Press. Retrieved from http://soltreemrls3.s3-website-us-west-2.amazonaws.com/solutiontree.com/media/pdf/study_guides/21st_Century_Skills_Study_Guide. pdf.

[46] Gardner, H. (2006). World Library of Educationalists Series. The development and education of the mind: The selected works of Howard Gardner. Routledge/Taylor \& Francis Group.

[47] Savva, A. (2009). Children's responses to visual images: Preferences, functions and origins. Retrieved from ttp://www.interdisciplinary.net/wpcontent/uploads/2009/06/andri-savvalasttemplate15.pdf.
[48] Ramsey, I.L. (1982). Effect of Art Style on children's picture preferences. The Journal of Educational Research, 75(4), 237-240. Retrieved from https://www.jstor.org/stable/27539901.

[49] Wright, S. (2010). Understanding creativity in early childhood: Meaning-making and children's drawings. London: Sage Publications. Retrieved from https://books.google.co.in/books/about/Understanding_Creativity_in_ Early_Childh.html?id=DwrIev8fXEQC\&redir_esc=y.

[50] Yenawine, P. (2003). Jump starting visual literacy: Thoughts on image selection. Art Education, 56(1), 6-12. doi: 10.1080/00043125.2003.11653478.

[51] Eisen, S.L, Ulrich, R., Shepley, M.M., Varni, J.W., \& Sherman, S. (2008). The stress-reducing effects of art in paediatric health care: Art preferences of healthy children and hospitalized children. Journal of Child Health Care, 12(3): 173-190. doi:10.1177/1367493508092507.

[52] Leder, H., Gerger, G., Dressler, S., \& Schabmann, A. (2012). How art is appreciated. Psychology of Aesthetics, Creativity, and the Arts, 6(1): 2-10. doi:10.1037/a0026396.

[53] Leder, H. \& Nadal, M. (2014). Ten years of a model of aesthetic appreciation and aesthetic judgments: The aesthetic episodeDevelopments and challenges in empirical aesthetics. British Journal of Psychology, 105(4), 443-464. doi: 10.1111/bjop.12084.

[54] Leder, H., Belke, B., Oeberst, A., \& Augustin, D. (2004). A model of aesthetic appreciation and aesthetic judgments. British Journal of Psychology, 95, 489-508. doi:10.1348/0007126042369811.

[55] Augustin, M. D. \& Leder, H. (2006). Art expertise: a study of concepts and conceptual spaces. Psychological Science, 48, 135-156. Retrieved from https://www.researchgate.net/publication/26514489.

[56] Parsons, M. J. (1994). Can children do aesthetics? a developmental account. Journal of Aesthetic Education, 28, 33-45. Retrieved from http://www.jstor.org/stable/3333399.

[57] Wang, W. \& Ishizaki, K. (2002). Aesthetic development in crosscultural contexts: A study of art appreciation in Japan, Taiwan, and the United States. Studies in Art Education, 43(4): 373-391. doi: $10.2307 / 1320984$ 